\title{
Ocorrência de bactérias solubilizadoras de fosfato nas raízes de plantas de importância econômica em Manaus e Rio Preto da Eva, Amazonas
}

\author{
Ana Cristina Souza da Silva ${ }^{1}$, Aloisio Freitas Chagas Junior ${ }^{2 *}$, Luiz Antonio de Oliveira ${ }^{3}$ e \\ Lillian França Borges Chagas ${ }^{2}$
}

${ }^{1}$ Universidade Federal do Amazonas (UFAM); 69010-110; Manaus - AM - Brasil. ${ }^{2}$ Universidade Federal do Tocantins - Campus de Gurupi; 77402-970; Gurupi - TO - Brasil. ${ }^{3}$ Instituto Nacional de Pesquisas da Amazônia INPA/CPCA; 69011-970; Manaus - AM - Brasil.

\begin{abstract}
Aiming at understanding the ecology of phosphate solubilizing bacteria (BSF), the study to evaluate the occurrence of BSF in the roots of plants on properties in the cities of Manaus and Rio Preto da Eva, Amazonas. The roots were cut into $1 \mathrm{~cm}$ pieces and placed in petri dishes with two types of culture medium containing an aluminum phosphate, pH 4.5 (P-Al) and, the other, calcium phosphate, pH $6.5(P-C a)$. Then we observed the presence of BSFs in each culture medium. The results show that the presence of BSF varies with location and species studied. The occurrence of bacteria solubilizing calcium phosphate was higher than the solubilization of aluminum phosphate
\end{abstract}

Key words: Phosphorus, Amazon, soil bacteria, microbial ecology

\section{INTRODUÇÃO}

Os microrganismos do solo são responsáveis, direta ou indiretamente, por inúmeros processos biológicos de grande importância para o funcionamento e capacidade produtiva dos ecossistemas terrestres. A atividade biológica do solo é um termo geral que "inclui todas as reações metabólicas, suas interações e processos bioquímicos mediados ou realizados diretamente pelos organismos do solo" (Moreira e Siqueira, 2006). As bases dos processos biológicos do solo são o crescimento microbiano e as transformações orgânicas e inorgânicas por eles mediados.

No contexto da fertilidade do solo e nutrição vegetal, os microrganismos podem atuar como "facilitadores" da nutrição, interferindo na disponibilidade e contribuindo, assim, para reduzir a necessidade ou maximizar o uso de fertilizantes manufaturados (Moreira e Siqueira, 2006). Estes efeitos resultam de suas atividades na rizosfera e do estabelecimento de relações simbióticas, em especial com as raízes, como a fixação biológica do nitrogênio, a formação de micorrizas e a solubilização de fosfatos (Souchie et al., 2007).

$\mathrm{O}$ efeito positivo da atividade dos microrganismos na rizosfera geralmente traz vantagens, tanto para o crescimento da planta, quanto para a atividade microbiana. A produção de aminoácidos, ácidos orgânicos, vitaminas e hormônios pelos microrganismos (Souchie et al. 2006), assim como a dissolução de fosfatos, que os torna disponíveis para as plantas (Souchie et al., 2007; Barroso e Nahas, 2008; Chagas Jr et al., 2010), são de grande importância para o crescimento da planta.

Além de solubilizar fosfato de cálcio, mecanismo adequado para solos alcalinos, microrganismos do solo podem, também, solubilizar fosfato de ferro, de alumínio, de magnésio e outros (Gyaneshwar et al., 2002; Vessey, 2003; Chagas Jr et al., 2010), Desse modo, podem contribuir para a solubilização do fósforo nos solos ácidos e de baixa fertilidade dos trópicos, onde predominam os fosfatos de alumínio e ferro.

Considerando a existem de poucas informações sobre bactérias solubilizadoras de fosfato (BSF) na Amazônia, é preciso intensificar os estudos com essas bactérias na região, para que elas possam contribuir efetivamente para um melhor aproveitamento do $\mathrm{P}$ no solo pelas plantas. $\mathrm{O}$ primeiro passo dessas pesquisas é um estudo sobre a ecologia dessas bactérias, isto é, onde ocorrem e as freqüências de suas ocorrências.

Author for correspondence: chagasjraf@uft.edu.br 
Assim, o objetivo deste trabalho foi avaliar a ocorrência de bactérias solubilizadoras de fosfato nas raízes de plantas de pequenas propriedades rurais situadas na Estrada do Puraquequara, município de Manaus e no município do Rio Preto da Eva, ambos no Estado do Amazonas.

\section{MATERIAL E MÉTODOS}

Foram coletadas amostras de raízes e solo em propriedades rurais localizadas no Ramal do Brasileirinho, na estrada do Puraquequara (Zona rural de Manaus) e no município de Rio Preto da Eva (Km 80 - AM 010) no Estado do Amazonas e levadas para o Laboratório de Microbiologia do Solo da Coordenação de Pesquisas em Ciências Agronômicas (CPCA) do Instituto Nacional de Pesquisas da Amazônia (INPA).

Em cada propriedade as coletas foram em quatro espécies, e de cada espécie cinco plantas como repetições. Assim, em um período de seis meses e meio (agosto de 2009 a fevereiro de 2010), foram visitadas cinco propriedades no Puraquequara e quatro propriedades no Rio Preto da Eva, coletando-se 19 espécies de importância econômica, totalizando 151 plantas.

No laboratório, as raízes das diversas espécies anuais e perenes foram cortadas em pedaços de 1 $\mathrm{cm}$ e colocadas em placas de Petri (dez pedaços de cada planta por placa). O método consistiu em detectar bactérias solubilizadoras de fosfato (BSF) em placas de Petri utilizando-se os meios de cultura específicos. Um para se verificar a solubilização de fosfato de cálcio (P-Ca), meio GL, que continha $10 \mathrm{~g}$ de glucose, $2 \mathrm{~g}$ de extrato de levedura e $15 \mathrm{~g}$ de Agar. A este meio foram adicionadas uma solução contendo $0,25 \mathrm{~g} \mathrm{~L}^{-1}$ de $\mathrm{K}_{2} \mathrm{HPO}_{4}$ e outra contendo $1 \mathrm{~g} \mathrm{~L}^{-1}$ de $\mathrm{CaCl}_{2}$, ajuntando-se o pH para 6,5, com o intuito de se formar fosfato de cálcio precipitado (Chagas $\mathrm{Jr}$ e Oliveira, 2001; Hara e Oliveira, 2004).

$\mathrm{O}$ meio GL foi modificado para verificar a solubilização de fosfato de alumínio (P-Al). Este meio continha $10 \mathrm{~g}$ de manitol, $2 \mathrm{~g}$ de extrato de levedura, $6 \mathrm{~g}$ de $\mathrm{K}_{2} \mathrm{HPO}_{4}$ e $18 \mathrm{~g}$ de Agar. A este meio foram acrescentado, também, uma solução contendo 5,34 $\mathrm{g} \mathrm{AlCl}_{3}$ e o $\mathrm{pH}$ foi ajustado para 4,5 para formar o precipitado de fosfato de alumínio. A modificação do meio GL foi a fonte de açúcar e a utilização e quantidade de $\mathrm{AlCl}_{3}$ e, para que houvesse aproximadamente $1,4 \mathrm{cmol}_{\mathrm{c}}$ de $\mathrm{Al}$ no meio, concentração deste elemento encontrada nas principais classes de solos da Amazônia, servindo, assim, como parâmetro para as condições reais desse elemento na natureza.

Foram feitas observações diárias nas placas contendo as raízes para a retirada de estirpes que apresentaram solubilização. Se o fosfato insolúvel é adicionado em meio ágar, as estirpes responsáveis pela solubilização do fosfato são detectadas por uma zona clara produzida ao redor da colônia. O período de observações foi, em média, de três dias, variando em função dos níveis de crescimento da microbiota do rizoplano durante os ensaios.

\section{RESULTADOS E DISCUSSÃO}

$\mathrm{Na}$ localidade de Puraquequara, em Manaus, foram encontradas BSF capazes de solubilizar fosfato de cálcio (P-Ca) na rizosfera do cupuaçu (8\% das amostras), pupunha (10\% das amostras), manga (2\% das amostras) e café (32\% das amostras) na propriedade 1 . A porcentagem de amostras positivas no meio contendo fosfato de alumínio (P-Al) foi de $0 \%$ para todas as espécies observadas (Tabela 1). Na propriedade 2, foram encontradas amostras positivas tanto para solubilizar $\mathrm{P}-\mathrm{Ca}$ como de $\mathrm{P}-\mathrm{Al}$ nas espécies avaliadas, com exceção do ingá que apresentou amostras positivas somente no meio com P-Ca. Observa-se, também, que a porcentagem de solubilização de $\mathrm{P}-\mathrm{Al}$ foi menor que de $\mathrm{P}-\mathrm{Ca}$ para as plantas de ingá, cupuaçu e goiaba. No entanto, as amostras das plantas de abacate analisadas tiveram maior porcentagem de amostras positivas no meio P-Al (25\%) que no meio P-Ca (19\%) (Tabela 1).

Na propriedade 3, não houve ocorrência de BSF em nenhuma das espécies avaliadas. $\mathrm{Na}$ Propriedade 4, encontraram amostras positivas para as amostras de biribá (3\%), caju (1\%) e cana (2\%) no meio P-Al e apenas para as amostras de banana (6\%) no meio P-Ca (Tabela 1).

$\mathrm{Na}$ propriedade 5 , as espécies caju (9\%), café $(10 \%)$, urucum $(7 \%)$ e ingá $(21 \%)$ apresentaram amostras positivas no meio $\mathrm{P}-\mathrm{Ca}$, e somente ingá apresentou amostras positivas (2\%) no meio $\mathrm{P}-\mathrm{Al}$ (Tabela 1). 
Tabela 1. Ocorrência de bactérias solubilizadoras de fosfato em raízes de espécies coletadas em propriedades rurais do Puraquequara em Manaus-AM.

\begin{tabular}{|c|c|c|c|c|c|}
\hline Propriedade & Cultura & Meio & $\begin{array}{c}\text { N. de } \\
\text { Amostras }\end{array}$ & $\begin{array}{l}\text { \% de Amostras } \\
\text { Positivas }\end{array}$ & $\begin{array}{l}\text { pH do Solo } \\
\text { (água) }\end{array}$ \\
\hline \multirow{2}{*}{1} & Mamão (Carica papaya, Linn) & P-Al & 100 & 0 & 4,4 \\
\hline & & $\mathrm{P}-\mathrm{Ca}$ & 100 & 0 & 4,4 \\
\hline \multirow[t]{2}{*}{1} & $\begin{array}{l}\text { Cupuaçu (Theobroma } \\
\text { grandiflorum (Epreng.) Schm.)) }\end{array}$ & P-Al & 100 & 0 & 3,6 \\
\hline & & $\mathrm{P}-\mathrm{Ca}$ & 100 & 8 & 3,6 \\
\hline \multirow[t]{2}{*}{1} & $\begin{array}{l}\text { Pupunha (Bactris gasipaes, } \\
\text { Kunth) }\end{array}$ & $\mathrm{P}-\mathrm{Al}$ & 100 & 0 & 3,9 \\
\hline & & $\mathrm{P}-\mathrm{Ca}$ & 100 & 10 & 3,9 \\
\hline \multirow[t]{2}{*}{1} & Manga (Mangifera indica, Linn) & $\mathrm{P}-\mathrm{Al}$ & 100 & 0 & 3,9 \\
\hline & & $\mathrm{P}-\mathrm{Ca}$ & 100 & 2 & 3,9 \\
\hline \multirow[t]{2}{*}{1} & Café (Coffea canephora Pierre) & $\mathrm{P}-\mathrm{Al}$ & 100 & 0 & 3,7 \\
\hline & & $\mathrm{P}-\mathrm{Ca}$ & 100 & 32 & 3,7 \\
\hline \multirow[t]{2}{*}{2} & Ingá (Inga edulis Mart.) & $\mathrm{P}-\mathrm{Al}$ & 100 & 0 & 3,8 \\
\hline & & $\mathrm{P}-\mathrm{Ca}$ & 100 & 39 & 3,8 \\
\hline \multirow[t]{2}{*}{2} & $\begin{array}{l}\text { Cupuaçu (Theobroma } \\
\text { grandiflorum (Epreng.) Schm.)) }\end{array}$ & $\mathrm{P}-\mathrm{Al}$ & 100 & 15 & 3,8 \\
\hline & & $\mathrm{P}-\mathrm{Ca}$ & 100 & 27 & 3,8 \\
\hline \multirow[t]{2}{*}{2} & Goiaba (Psidium guajava, Linn) & $\mathrm{P}-\mathrm{Al}$ & 100 & 21 & 3,9 \\
\hline & & $\mathrm{P}-\mathrm{Ca}$ & 100 & 28 & 3,9 \\
\hline \multirow[t]{2}{*}{2} & $\begin{array}{l}\text { Abacate (Persea gratissima, } \\
\text { Gaentin) }\end{array}$ & $\mathrm{P}-\mathrm{Al}$ & 100 & 25 & 3,8 \\
\hline & & $\mathrm{P}-\mathrm{Ca}$ & 100 & 19 & 3,8 \\
\hline \multirow[t]{2}{*}{3} & Acerola (Malpighia glabra L.) & $\mathrm{P}-\mathrm{Al}$ & 100 & 0 & 4,6 \\
\hline & & $\mathrm{P}-\mathrm{Ca}$ & 100 & 0 & 4,6 \\
\hline \multirow[t]{2}{*}{3} & $\begin{array}{l}\text { Jambo (Eugenia malaccensis, } \\
\text { Linn) }\end{array}$ & $\mathrm{P}-\mathrm{Al}$ & 100 & 0 & 3,9 \\
\hline & & $\mathrm{P}-\mathrm{Ca}$ & 100 & 0 & 3,9 \\
\hline \multirow[t]{2}{*}{3} & $\begin{array}{l}\text { Cupuaçu } \\
\text { grandiflorum (Epreng.) Schm.)) }\end{array}$ & $\mathrm{P}-\mathrm{Al}$ & 100 & 0 & 4,1 \\
\hline & & $\mathrm{P}-\mathrm{Ca}$ & 100 & 0 & 4,1 \\
\hline \multirow[t]{2}{*}{3} & $\begin{array}{l}\text { Laranja (Citrus sinensis, (Linn) } \\
\text { Osbeck) }\end{array}$ & $\mathrm{P}-\mathrm{Al}$ & 100 & 0 & 3,9 \\
\hline & & $\mathrm{P}-\mathrm{Ca}$ & 100 & 0 & 3,9 \\
\hline \multirow[t]{2}{*}{3} & Manga (Mangifera indica, Linn) & P-Al & 100 & 0 & 4,2 \\
\hline & & $\mathrm{P}-\mathrm{Ca}$ & 100 & 0 & 4,2 \\
\hline \multirow[t]{2}{*}{4} & $\begin{array}{l}\text { Biribá (Rollinea mисоsa (Jacq.) } \\
\text { Baill) }\end{array}$ & $\mathrm{P}-\mathrm{Al}$ & 100 & 3 & 4,2 \\
\hline & & $\mathrm{P}-\mathrm{Ca}$ & 100 & 0 & 4,2 \\
\hline \multirow[t]{2}{*}{4} & $\begin{array}{l}\text { Cacau (Theobroma cacau, } \\
\text { Linn.) }\end{array}$ & $\mathrm{P}-\mathrm{Al}$ & 100 & 0 & 4,4 \\
\hline & & $\mathrm{P}-\mathrm{Ca}$ & 100 & 0 & 4,4 \\
\hline \multirow[t]{2}{*}{4} & $\begin{array}{l}\text { Caju (Anacardium occidentale, } \\
\text { Linn) }\end{array}$ & $\mathrm{P}-\mathrm{Al}$ & 100 & 1 & 3,9 \\
\hline & & $\mathrm{P}-\mathrm{Ca}$ & 100 & 0 & 3,9 \\
\hline \multirow[t]{2}{*}{4} & Cana (Sacarum officinarum L.) & P-Al & 100 & 2 & 4,7 \\
\hline & & $\mathrm{P}-\mathrm{Ca}$ & 100 & 0 & 4,7 \\
\hline \multirow[t]{2}{*}{4} & Banana (Musa sp.) & P-Al & 100 & 0 & 4,6 \\
\hline & & $\mathrm{P}-\mathrm{Ca}$ & 100 & 6 & 4,6 \\
\hline 5 & Caju (Anacardium occidentale, & $\mathrm{P}-\mathrm{Al}$ & 100 & 0 & 3,5 \\
\hline
\end{tabular}




\begin{tabular}{cllccc}
\multirow{2}{*}{ Linn) } & P-Ca & 100 & 9 & 3,5 \\
5 & Café (Coffea canephora Pierre) & P-Al & 100 & 0 & 3,6 \\
& & P-Ca & 100 & 10 & 3,6 \\
5 & Urucum (Bixa orelana L.) & P-Al & 100 & 0 & 4,0 \\
& & P-Ca & 100 & 7 & 4,0 \\
5 & \multirow{2}{*}{ Ingá (Inga edulis Mart.) } & P-Al & 100 & 2 & 4,3 \\
& & P-Ca & 100 & 21 & 4,3 \\
\hline
\end{tabular}

Média de cinco repetições. Meio P-Al com $\mathrm{pH}=4,5+2 \mathrm{cmol}_{\mathrm{c}} \mathrm{Al} \cdot \mathrm{L}^{-1}$. Meio P-Ca com pH=6,5

Nas propriedades de Rio Preto da Eva foram de cupuaçu $(13,8 \%$ e 5,5\%), no meio contendo Pencontradas amostras positivas apenas em plantas

$\mathrm{Ca}$ (Tabela 2).

Tabela 2. Ocorrência de bactérias solubilizadoras de fosfato em raízes de espécies coletadas em propriedades rurais do Rio Preto da Eva.

\begin{tabular}{|c|c|c|c|c|c|}
\hline Propriedade & Cultura & Meio & $\begin{array}{c}\text { N. de } \\
\text { Amostras }\end{array}$ & $\begin{array}{l}\% \text { de Amostras } \\
\text { Positivas }\end{array}$ & $\begin{array}{l}\text { pH do Solo } \\
\text { (água) }\end{array}$ \\
\hline \multirow[t]{2}{*}{1} & Pupunha (Bactris gasipaes, Kunth) & P-Al & 100 & 0 & 4,4 \\
\hline & & $\mathrm{P}-\mathrm{Ca}$ & 100 & 0 & 4,4 \\
\hline \multirow[t]{2}{*}{1} & $\begin{array}{l}\text { Laranja (Citrus sinensis, } \quad \text { (Linn) } \\
\text { Osbeck) }\end{array}$ & $\mathrm{P}-\mathrm{Al}$ & 100 & 0 & 4,5 \\
\hline & & $\mathrm{P}-\mathrm{Ca}$ & 100 & 0 & 4,5 \\
\hline \multirow[t]{2}{*}{1} & $\begin{array}{l}\text { Cupuaçu (Theobroma grandiflorum } \\
\text { (Epreng.) Schm.)) }\end{array}$ & $\mathrm{P}-\mathrm{Al}$ & 100 & 0 & 4,7 \\
\hline & & $\mathrm{P}-\mathrm{Ca}$ & 100 & 13,8 & 4,7 \\
\hline \multirow[t]{2}{*}{2} & Manga (Mangifera indica, Linn) & $\mathrm{P}-\mathrm{Al}$ & 100 & 0 & 4,3 \\
\hline & & $\mathrm{P}-\mathrm{Ca}$ & 100 & 0 & 4,3 \\
\hline \multirow[t]{2}{*}{2} & $\begin{array}{l}\text { Guaraná (Paullinea cupana var. } \\
\text { sorbilis) }\end{array}$ & $\mathrm{P}-\mathrm{Al}$ & 100 & 0 & 3,7 \\
\hline & & $\mathrm{P}-\mathrm{Ca}$ & 100 & 0 & 3,7 \\
\hline \multirow[t]{2}{*}{2} & $\begin{array}{l}\text { Abacate (Persea Gratissima, } \\
\text { Gaentin) }\end{array}$ & $\mathrm{P}-\mathrm{Al}$ & 100 & 0 & 4,5 \\
\hline & & $\mathrm{P}-\mathrm{Ca}$ & 100 & 0 & 4,5 \\
\hline \multirow[t]{2}{*}{3} & $\begin{array}{l}\text { Laranja (Citrus } \quad \text { sinensis, } \quad \text { (Linn) } \\
\text { Osbeck) }\end{array}$ & $\mathrm{P}-\mathrm{Al}$ & 100 & 0 & 5,6 \\
\hline & & $\mathrm{P}-\mathrm{Ca}$ & 100 & 0 & 5,6 \\
\hline \multirow[t]{2}{*}{3} & $\begin{array}{l}\text { Cupuaçu (Theobroma grandiflorum } \\
\text { (Epreng.) Schm.)) }\end{array}$ & $\mathrm{P}-\mathrm{Al}$ & 100 & 0 & 5,8 \\
\hline & & $\mathrm{P}-\mathrm{Ca}$ & 100 & 5,5 & 5,8 \\
\hline \multirow[t]{2}{*}{3} & Côco (Cocos nucifera L.) & $\mathrm{P}-\mathrm{Al}$ & 100 & 0 & 6,4 \\
\hline & & $\mathrm{P}-\mathrm{Ca}$ & 100 & 0 & 6,4 \\
\hline \multirow[t]{2}{*}{4} & $\begin{array}{l}\text { Laranja (Citrus sinensis, } \quad \text { (Linn) } \\
\text { Osbeck) }\end{array}$ & $\mathrm{P}-\mathrm{Al}$ & 100 & 0 & 4,6 \\
\hline & & $\mathrm{P}-\mathrm{Ca}$ & 100 & 0 & 4,6 \\
\hline \multirow[t]{2}{*}{4} & $\begin{array}{l}\text { Cupuaçu (Theobroma grandiflorum } \\
\text { (Epreng.) Schm.)) }\end{array}$ & $\mathrm{P}-\mathrm{Al}$ & 100 & 0 & 4,4 \\
\hline & & $\mathrm{P}-\mathrm{Ca}$ & 100 & 0 & 4,4 \\
\hline \multirow[t]{2}{*}{4} & Graviola (Annona muricata, Linn) & $\mathrm{P}-\mathrm{Al}$ & 100 & 0 & 4,3 \\
\hline & & $\mathrm{P}-\mathrm{Ca}$ & 100 & 0 & 4,3 \\
\hline
\end{tabular}

Média de cinco repetições. Meio P-Al com pH $=4,5+2$ cmol $_{c}$ Al. $L^{-1}$. Meio P-Ca com pH= 6,5

As raízes das 151 plantas das 19 espécies vegetais foram efetivamente testadas em meio de cultura específicos para solubilizadores de P-Ca e P-Al.

Das 6040 amostras de raízes analisadas quanto à 
ocorrência de BSF, 294 (6,73\%) apresentaram atividade positiva nas condições testadas. Para o grupo de Puraquequara, das 4600 amostras de raízes testados, $287(6,24 \%)$ apresentaram amostras positivas quanto à solubilização de fosfato de cálcio e/ou alumínio. O grupo de Rio Preto da Eva teve $12(0,5 \%)$ amostras positivas das
2400 analizadas. Estes dois grupos de amostras foram coletados de locais distintos e mostram uma diversidade com relação à ocorrência de bactérias solubilizadoras de fosfatos (Tabela 3) em diferentes espécies de plantas e condições de solos na Amazônia.

Tabela 3. Relação do material biológico pesquisados por local de coleta.

\begin{tabular}{lccccc}
\hline \multicolumn{1}{c}{ Coletas } & N. de espécies & N. de plantas & $\begin{array}{c}\text { Total de } \\
\text { amostras }\end{array}$ & $\begin{array}{c}\text { Amostras } \\
\text { positivas }\end{array}$ & \% positivas \\
\hline Puraquequara & 17 & 23 & 4600 & 287 & 6,24 \\
Rio Preto da Eva & 8 & 12 & 2400 & 12 & 0,50 \\
\hline Total & & 35 & 7000 & 294 & 6,74
\end{tabular}

Vários estudos (Ilmer et al., 1995; Kim et al., 1999; Silva Filho e Vidor, 2000; Silva Filho et al., 2002; Hara e Oliveira, 2004, 2005) evidenciam que a capacidade dos isolados de bactérias do solo solubilizarem o P-Ca está correlacionada com a diminuição do pH do meio pelos ácidos orgânicos. Os ácidos orgânicos secretados podem diretamente dissolver o fosfato mineral como resultado da troca de anion de $\mathrm{PO}_{4}^{-2}$ por anion ácido ou pode quelatar íons de $\mathrm{Fe}^{2+/ 3+}$ e $\mathrm{Al}^{3+}$ associados com fosfatos.

Os resultados encontrados nas diferentes propriedades estudadas, nas duas localidades, mostraram que em algumas raízes de plantas foi possível obter resposta positiva para a ocorrência de BSF capazes de solubilizar tanto o P-Ca, quanto o P-Al. Porém, dentre as amostras positivas, somente as amostras das espécies cupuaçu, goiaba, abacate, biribá, cana e ingá apresentaram crescimento e solubilização de P-Al (Tabela 1 e 2). É muito provável que o efeito microbiano na rizosfera de plantas pode proporcionar uma resposta fisiológica positiva nas plantas hospedeiras, como a capacidade de solubilizar fosfatos inorgânicos, disponibilizando-os para as plantas (Silva Filho et al., 2002; Vessey, 2003). Assim, a avaliação de bactérias do solo a partir da avaliação "in vitro" da capacidade de solubilização de fosfatos pode proporcionar uma base segura para selecionar isolados de bactérias solubilizadoras de fosfatos efetivos. Porém, há a necessidade de se estudar o uso dessas bactérias como inoculantes, enfocando os mecanismos de sobrevivência em solos da região amazônica, para que se possa selecionar isolados que possam solubilizar o fósforo insolúvel.

Dando continuidade ao processo de isolamento das BSF para uma posterior seleção das linhagens, principalmente das que apresentaram solubilização de fosfato de alumínio (crescimento em meio P$\mathrm{Al}$ ), evidenciando certa tolerância ao $\mathrm{pH}$ e $\mathrm{Al}$ tóxico encontrados nos solos regional, essas bactérias podem contribuir para o aumento da disponibilidade do P no solo. Além disso, levanta a possibilidade de que algumas dessas bactérias podem aumentar o $\mathrm{pH}$ da rizosfera, com conseqüente neutralização, parcial ou total, do Al tóxico e da acidez, de magnitude suficiente para alterar a habilidade das plantas para absorver o $\mathrm{P}$ a partir do solo. Esses resultados promissores mostram a necessidade de continuar e intensificar os estudos com BSF.

\section{CONCLUSÕES}

Os resultados obtidos nesse trabalho mostram que a presença de BSF varia com o local e espécies vegetais e com as condições do solo de onde foi realizada a coleta.

A ocorrência de bactérias solubilizadoras de fosfato de cálcio foi maior do que as que solubilizaram fosfato de alumínio.

\section{RESUMO}

Visando o conhecimento da ecologia de bactérias solubilizadoras de fosfato (BSF), o trabalho teve como objetivo avaliar a ocorrência de BSF nas raízes de plantas em propriedades nos municípios de Manaus e Rio Preto da Eva, Amazonas. As raízes foram cortadas em pedaços de $1 \mathrm{~cm}$ e colocadas em placas de petri com 
dois tipos de meio de cultura, um contendo fosfato de alumínio e $\mathrm{pH}$ 4,5 (P-Al) e, o outro, fosfato de cálcio, $\mathrm{pH}$ 6,5 $(\mathrm{P}-\mathrm{Ca})$. Em seguida foi observada a presença das BSFs em cada meio. Os resultados mostram que a presença de BSF varia com o local e as espécies vegetais estudadas. A ocorrência de bactérias solubilizadoras de fosfato de cálcio foi maior do que as que solubilizaram fosfato de alumínio.

Palavras-chave: Fósforo, Amazônia, bactéria do solo, ecologia microbiana

\section{REFERÊNCIAS}

Barroso, C. B. e Nahas, E. (2008), Solubilização de fosfatos de ferro em meio de cultura. Pesquisa Agropecuária Brasileira, 43, 529-535.

Chagas Jr, A. F. e Oliveira, L. A. (2001), Tolerância de bactérias solubilizadoras de fosfato à acidez de alumínio. Revista da Universidade Federal do Amazonas: Ciências Agrárias $e$ Ambientais, 1, 39-51.

Chagas Jr, A. F.; Oliveira, L. A.; Oliveira, A. N.; Willerding, A. L. (2010), Capacidade de solubilização de fosfatos e eficiência simbiótica de rizóbios isolados de solos da Amazônia. Acta Scientiarum. Agronomy, 32, 359-366.

Gyaneshwar, P.; Kumar, G. N.; Parekh, L. J.; Poole, P. S. (2002), Role of soil microorganisms in improving P nutrition of plant. Plant and Soil, 245, 83-93.

Hara, F. A. S. e Oliveira, L. A. (2004), Características fisiológicas e ecológicas de isolados de rizóbios oriundos de solos ácidos e álicos de Presidente Figueiredo, Amazonas. Acta Amazônica, 34, 343-357.

Hara, F. A. S. e Oliveira, L. A. (2005), Características fisiológicas e ecológicas de isolados de rizóbios oriundos de solos ácidos de Iranduba, Amazonas. Pesquisa Agropecuária Brasileira, 40, 667-672.
Ilmer, P.; Barbato, A.; Schinner, F. (1995), Solubilization of hardly-soluble $\mathrm{AlPO}_{4}$ with Psolubilizing microorganisms. Soil Biology and Biochemistry, 27, 265-270.

Kim, K. Y.; Mcdonald, G. A.; Jordan, D. (1999), Solubilization of hydroxyapatite by Enterobacter agglomerans and cloned $E$. coli in culture medium. Biology and Fertility of Soil, 24, 347352.

Moreira, F. M. de S. e Siqueira, J. O. (2006), Microbiologia e bioquímica do solo. 2. ed. Lavras: UFLA. 729p.

Silva Filho, G. N. e Vidor, C. (2000), Solubilização de fosfatos por microrganismos na presença de fontes de carbon. Revista Brasileira de Ciência do Solo, 24, 311-319.

Silva Filho, G. N.; Narloch, C.; Scarf, R. (2002), Solubilização de fosfatos naturais por microrganismos isolados de cultivos de Pinus e Eucalyptus de Santa Catarina. Pesquisa Agropecuária Brasileira. Brasíliam, 37, 847-854.

Souchie, E. L.; Abboud, A. C. S.; Caproni, A. L. (2007), Solubilzadores de fosfatos in vitro por microrganismos rizosféricos de guandu. Bioscience Journal, 23, 53-60.

Souchie, E. L.; Azcón, R.; Barea, J. M.; SagginJunior, O. J.; Silva, E. M. R. (2006), Phosphate solubilization and synergism between Psolubilizing and arbuscular mycorrhizal fungi. Pesquisa Agropecuária, 41, 1405-1411.

Vessey, J. K. (2003), Plant growth promoting rhizobacteria as biofertilizers. Plant and Soil, 255, 571-586. 